\title{
Institutional Implications of an Automated Circulation Study
}

\begin{abstract}
In February 1965 Oakland University library implemented a circulation control system utilizing IBM 357 data collection units with a 1620 computer equipped with disk storage. An initial test run of analytic by-products of the system shows implications for more efficient library administration and further defines the library's function in the educational process.
\end{abstract}

$\mathrm{T}$ HIS PAPER is a report, based on initial, limited data, of a few of the questions and answers made economically possible through the combination of machinereadable circulation and student records at Oakland University. The specific answers to the questions asked in this study are of secondary importance, except as their relative status may suggest general trends. The questions themselves, together with similar, more refined types of inquiries, are ones which become readily and regularly answerable with any circulation system that combines call number information with borrower identification in an easily tabulatable form.

In the case of the Oakland system, this transaction record is a punched card produced automatically from a machinereadable book card, a machine-readable borrower's card, and a time clock. Its primary function is input to the main circulation records system. By accumulating these cards after their information has been processed through the com-

Until July 1966 Dr. Cammack was University Librarian and Associate Professor of Linguistics at Oakland University, Rochester, Michigan. He is now on leave of $a b$ sence as a Fulbright Lecturer in Japan. Donald Mann is Assistant Director of Oakland's Computing and Data Processing Center and the designer of the system described. puter, there develops a store of bookand-borrower data which in turn can be run against student records containing current information on grades, curriculum, and class.

The analyses performed thus far are basically counting mechanisms. The approach to each analysis was to determine, within the charge data, the possible span of the quality- or identifierfield to be analyzed, such as the day of charge, class of book charged, etc. A counter for each unit of the span was set up in computer memory, the file of charge cards was passed through the computer, which incremented the appropriate counter for each charge, and the contents of the counters were then printed.

No forecasting or statistical analysis was done by computer at this time. The study merely lends insight into the relative volumes of the various characteristics of the data. By establishing the counters in memory prior to giving the data to the computer on each run, the necessity of large-scale card sorting was all but eliminated. All programs were written in the FORTRAN programing language and were run on the university IBM 1620 computer which has card, disk, and printer capacity.

The charge cards were first separated from the discharge cards. Three analyses 
were then made on the charges: Use by Day (run time: $50 \mathrm{~min}$.), Use by LC Class ( $85 \mathrm{~min}$.), and Use by Time of Day ( $55 \mathrm{~min}$.). The charges for students were then split out and sorted into student number sequence. These cards were then run against the student cumulative performance file which is maintained by the university, and student summary cards were punched. These cards contain student number, number of charges, cumulative Grade Point Average, curriculum, and class. The remaining four analyses were then run: Use by GPA (20 min.), GPA by Use ( $20 \mathrm{~min}$.), Use by Class ( $20 \mathrm{~min}$.), and Use by Curriculum (20 min.). Copies of detailed data not presented here can be made available on request.

The initial tabulations, after four months of operation, provided answers to the following inquiries.

Question: Could personnel scheduling at public service desks be more efficiently or economically handled?

Answer: Yes. A tabulation of dates of charges showed a striking consistency by which charging activity tended to follow a cyclical pattern, consistently giving certain days of the week by far the heaviest workloads. Desk staffing patterns and shelving labor could be brought into better relationship with an unexpectedly predictable activity cycle. In answer to the same question, the number of changes per hour showed four regular peaks with definite implications for desk staffing and improved closing procedures. Unexpectedly, and in contradiction to the staff's impressions, charging activity did not tend to cluster around class intervals, but spread quite evenly throughout each hour of the service day.

Question: Which portions of the library's collections are used most heavily, and which are used least?

Answer: A breakdown by LC classification letters showed English literature, history, philosophy, education, and economics topping the list in that order. The lowest significant use areas involved mathematics and the physical sciences, the totality of which did not equal use in English literature alone.

Such an answer might well raise a number of subsidiary questions concerning adequacy of the collection for student use, library orientation for science students, comparative figures for similar institutions, the numerical relation of science majors to other majors, and perhaps the science faculty's awareness of the library's resources together with the whole question of departmental goals and book budget allocations.

Question: Students majoring in which subjects tend to be the heaviest library users, and does this correlate as expected with the answer to the immediately preceding question?

Answer: Secondary education majors in modern foreign languages and English head the list for average number of charges per person, followed closely by liberal arts majors in the same fields. Similarly high averages support history and philosophy use patterns mentioned above. Majors in physical and biological sciences average below the mean, but again with their secondary education counterparts somewhat more active than students in the College of Arts and Sciences.

The suggested implications of these tabulations would appear to be that students tend to read largely within their own fields of study (although a further breakdown by individual students' charge records would be required to confirm the conclusion) and that, at Oakland at any rate, students planning teaching careers use the library more than arts and sciences students with the same subject specialization.

Question: Do upperclassmen tend to use the library more than lowerclassmen? 
Answer: Decidedly yes. Of those who used the library during the list period, juniors and seniors averaged almost twice the number of charges for freshmen and sophomores. Somewhat more enlightening are the implications of the class breakdown shown in Figure 1 below. The freshman year would appear to be a "non-library" year, in at least a portion of which only 10 per cent of the class found it necessary to check out a library book. By the sophomore year, the number has increased sharply and by the junior year, apparently almost all students are library borrowers. With the implementation in 1966 of a new lower division curriculum at Oakland, it would seem worthwhile to establish a detailed analysis of freshman library activity (or inactivity) in cooperation with the administrative officers responsible for the curriculum. The inclusion of librarians

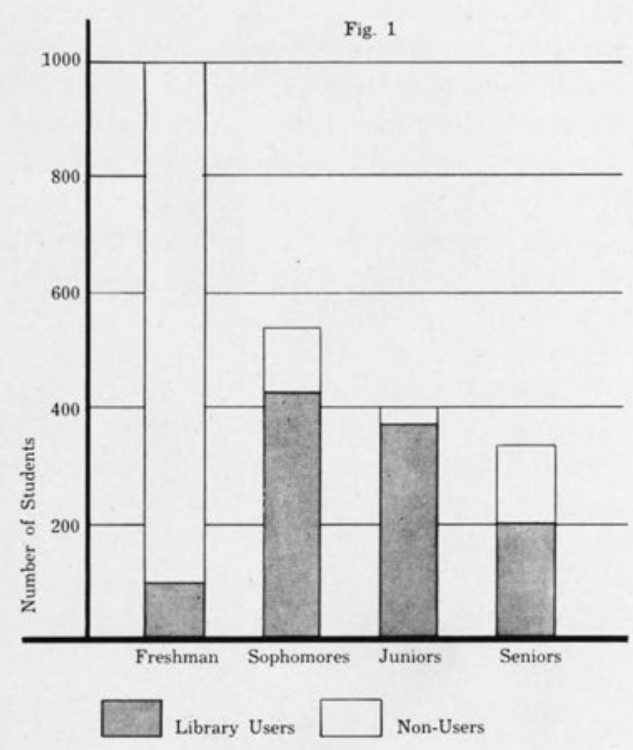

data shows a direct, positive correlation between the borrowing of library materials and cumulative grade point average. Using the test period as a sample, the cumulative GPA of students who borrowed at least one book during the time was 2.73 , while that for students who borrowed no books during the period was 2.54 ; implying again that regular 
library borrowers are likely to make better grades than do nonborrowers. It may also be that entrance examination scores are higher for the former group. A semester-by-semester tabulation of these relationships could begin to establish profiles of student achievement by classyear and subject. Further sorting of data could provide individual "reading profiles" for individual students and groups of students, answering in part the old question "What does a 'good' student do that a 'bad' student doesn't?"-and vice versa.

Sidestepping for the moment any discussion of causal relationships between academic achievement and library use, the library's position (if not function) within the undergraduate educational process would appear, simply on the basis of circulation figures, to be demonstrably significant. When this correlation is viewed in connection with freshman and sophomore use patterns, perhaps academic librarians (at least at Oakland) should set out to "recruit" users in their first two years of college work. It might well be that college librarians should take another look at the public library's operation and staffing of young adult collections.

As the store of transaction data continues to increase as a by-product of the circulation system, it will soon reach the point at which reliable answers can be found to a number of additional questions. The ability to identify nonborrowers quickly and accurately should provide useful information for academic advisers. The borrowing records for commuters, dormitory students, students in specific courses, part-time students, and faculty members are within easy access, allowing runs of the total accumulation of data or of any desired sample. While most manual circulation systems generate the same type of data, machinereadable data allow easy and rapid tabulation at a fraction (estimated at $1 / 5$ ) of the cost of the same information developed manually. Initial faculty and administrative reaction to the availability of this type of information has very quickly answered the question, "Who cares?" Requests for special runs have ranged from the professor who asked for periodic "traffic reports" on his assigned reading lists to a department chairman who expressed a near-unethical degree of interest in the reading habits of his faculty members in connection with promotion decisions.

With the system designed to go online as soon as practicable, the provision of remote terminals could put the answers to these and many other questions literally at the fingertips of librarians, administrators, and faculty members, with data always up-to-date and instantly available. 